\title{
Three Application Scenarios for Use in the myCourse Educational Environment
}

\author{
doi:10.3991/ijet.v6i1.1531 \\ Thanasis Giouvanakis ${ }^{1,2}$, Garyfallos Fragidis ${ }^{2}$ and Adamantios Koumpis ${ }^{3}$ \\ ${ }^{1}$ University of Macedonia, Thessaloniki, Greece \\ ${ }^{2}$ Institute of Technology and Education, Serres, Greece, \\ ${ }^{3}$ Research Programmes Division, ALTEC Software S.A., Thessaloniki, Greece
}

\begin{abstract}
In order for a user to develop rich and valid knowledge structures, not only is considerable predefined content required, but other equally important types of knowledge as well. In other words, to display real understanding and to build and extend their knowledge structures, users have to call on several resources as well as representation, retrieval and construction mechanisms. Apart from the specific content, on which traditional educational environments focus on, a user depends heavily on general content knowledge and on systems of knowledge that is more abstract and elusive than typical content. In this article, we document our myCourse approach presenting three application scenarios. In these scenarios, knowledge creation is a process of emergence and co-evolution of the individual, the social group and the wider society.
\end{abstract}

Index Terms-User Generated Content, Social networking, Educational services, Service Oriented Architectures.

\section{INTRODUCTION}

The idea of myCourse has been presented in [1] where its characteristics have been presented accompanied by its functionality profile as a social networking learning platform for developing services which address the personal learning needs of a variety of user categories and enable them to create value. myCourse has been described with respect to the specific characteristics sought for a community driven educational service framework and the approach has been examined in comparison to other similar approaches and frameworks. In this paper we aim to describe three different application scenarios that have been developed on top of myCourse with the special aim to make use of its unique characteristics.

In a world that is dominated by the paradigm of open source computing [2], people's incentives to invest on a platform and then capitalise on the efficiencies that such a platform may enable has been seriously reduced if not damaged at all. Neither individuals nor enterprises or organisations are any more willing to spend resources on the creation of infrastructural elements such as the design and development of an educational content platform. Why invest in such a project when it is much easier and straightforward to choose a freely available one and customise it to meet your needs?

We are not against this attitude - quite the contrary all authors have participated in projects that made extensive and heavy use of this approach (see for instance [3] and [4]). However, following this path brings certain difficulties the most obvious of which is the lack of increased control and expressive power in the design of derived services on top of the particular platform. This seems of marginal importance in the beginning of several projects but sooner or later will become the most influential killing factor for the entire project [5]. It is this last reason that motivated us in the implementation of the myCourse environment and in the following three sections we shall describe three different application scenarios that have been designed to "run" on top of it.

The test application scenarios cover three business areas, namely those of finance, tourism and employment services. These services will eventually be explorable, usable, reviewable, and mash-up-able by other public users that will employ myCourse in their organisations.

\section{MYCOURSE USE CASE IN THE AREA OF FINANCE}

Even if several financial services exist, such as ebanking, e-trading, Forex, etc, these services are still nonconfigurable by the end user and represent the business logic view without a consideration of customer needs, in a silo manner and hardly, if not impossibly, interconnected by the end user. By end users, we consider both customers and the financial operators (middle office and back office).

In the pilot scenario deployed using the myCourse platform two major issues are addressed:

1. Inter-organizational financial services: back and middle officers belonging to several financial institutions proceed manually to the collection and the composition of their services. This is usually done by direct contacts between them, under different data and information exchanges and by composing their services according to their own compliance rules. This usually leads to a long realization time, incomprehension and loss of efficiency. Moreover, most of the existing systems are hardly interconnected and operators need to bypass controls and verification to gain in flexibility and reactivity while dealing with other institutions. This situation could create either a complete isolated service, hardly reactive to its environment and not well adapted to customers or risky situations.

2. Composing financial services composing: to customize offered services to the end customer needs, customers have to separate their needs under a 'cellular' services form. By cellular we mean the elementary unit of a service that could be addressed and treated independently from the entire set of requested services. For example, a customer who wants to make a bill payment from two distinct accounts has to pro- 
ceed to a regrouping of the balance from these accounts and then to proceed to the bill payment. In more complex financial transactions (mortgage, trading, etc.) the problem of composing services can lead to a high level of complexity and a significantly increased implementation time.

Today, in the private banking sector, few added value activities are fully automated. The Markets in Financial Services Directive (hereafter referred to as MiFID) [6], which came into force in November 2007, provides a regulatory framework for the European securities market. The main objectives of the Directive are to increase competition within European capital markets and to enable firms to provide investment services throughout the 30 member States of the European Economic Area on the basis of the authorization granted by their home Member State, while ensuring higher levels of investor protection. Higher levels of investor protection entails that investment advice and portfolio management is achieved in accordance to the investor's level of experience, risk aversion or appetite and investment objectives. In addition, MiFID requires firms to convey fair, clear and not misleading information to investors as well as to categorize their clients either as retail clients, professional clients or eligible counterparts, a more specific type or professional client.

According to a survey [7] conducted among 33 European execution venues in the third quarter of 2007, the total costs related to the implementation of the directive reach approximately $1 \mathrm{M}$ EUR (i.e. per company surveyed) while annual ongoing costs for MIFID compliance are expected to be less than 100,000 EUR. Considering this investment, the majority of survey respondents view MIFID as "the possibility to expand into new business areas rather than see it as a regulatory burden". Similarly, we suggest turning MIFID regulation into an opportunity to foster service innovation and pursue the objective of developing or maintaining a sustainable competitive advantage by designing an instrument that would automatically map investor profile with new financial products.

Common characteristics to determine risk profile include customer wages, professional situation and stability, marital status, current charges in terms of mortgage or personal loans, tolerance to risk, willingness to obtain a guarantee on the capital to be invested, willingness to know the approximate return on investment, average investment horizon and so on.

The objective of this case study is to take advantage of the consequence of this regulation (i.e. client categorization) in order to inform customers automatically with products and services that are consistent with their profile.

Another example of myCourse usage is to automatically communicate information on relevant and attractive products, consistent with their profile, to the customer when he is logged in on the bank website. The use case plan is therefore as follows:

\section{A. Alternative financial use case plan}

This use case developed within the myCourse environment aimed to define the classification of existing financial products and their corresponding services. At this level detected overlapped services (inter-organisational and intra-organisational) are highlighted. This cartography of financial products and services serves as a landscape of the further development of financial service composition.
During the case study a special interest has been brought to specific investment vehicles that are the used by actors of the financial market in Luxembourg and Switzerland (UCITS, hedge, etc).

The objective was to automatically adapt the customer's service bundle according to his risk profile.

Current methods and practises consist in manual matching between risk profile and investment strategy (a set of financial products). These lead financial actors to carry on the matching without taking into account the evolution of customers situation and can generate a different and sometimes opposite investment strategy due to the lack of information. At this level, an identification of existing services mapping mechanisms between financial products specifications and customer are achieved. This is realized by analysing partners' activities and data, and identifying a set of actors' behaviour and knowledge. This set identifies the existing manners of composing services and the way the matching is achieved between the data and this set of services.

On the basis of the obtained schema and in order to enable automatic matching of investor profiles with new products and services, we need to build ontology's gathering and organizing (i) investor profile characteristics, (ii) financial products proprieties and (iii) and correspondence rules. These rules allow for identifying which product could interest an investor, according to his risk profile. These rules enable triggering of new product offer for each evolution of the investor profile.

We distinguish at this level two major guidelines for services development. The first is the development service corresponding to the existing financial products and the user's profile. The second concerns the development of a matching service based on the rules and ontology of the matching between them. All these data are gathered and experienced while using databases of customers of a financial institution with which we have a cooperation agreement.

The obtained services have been tested and simulated on real case to compare results between the usual actors behaviour and the observed actors behaviour while using the matching services. A sequential benchmarking matrix helps us to adjust the proposed matching service in order to reach a high conformity and performance level. This matrix is composed from the financial services evaluation criteria and results and is instantiated by using real data extracted partners systems and simulated data generated from services simulation step.

Based on the previous results this fosters interactive and dynamic marketing of financial services matching. In fact, this first scenario of applying myCourse helped junior trainee financial officers to react promptly to environment evolution. This includes the regulation and rules modification, customer's investment and risk profile adjustment and the creation of new financial investment services.

\section{MYCOURSE APPLIED IN TOURISM}

This second use case with myCourse specializes in providing an integrated environment for training of junior tourist managers when operating a Do It Yourself service platform for European and Chinese tourists to customize their travels and contribute to expand the tourism market share between the 2 regions, especially to induce more and more Chinese tourists to the European market by lev- 
eraging the abundant resources and unique communication ability of the social networking community.

Its functions include opportunities for travellers to customize their trip by planning their budget, selecting and combining their favourite resorts and hotels, establishing a network for travel-sharing, sharing tips and experiences in their blogs, sharing pictures and videos, and facilitating user to user assistance via the online community that use this service.

The social network users or organizations may use this service to establish their own $\mathrm{C} 2 \mathrm{C}, \mathrm{B} 2 \mathrm{C}$ and $\mathrm{B} 2 \mathrm{~B}$ business there for tourism related business such as tourism books, souvenirs, outdoor equipment and commodities, etc. It seamlessly integrates the upstream and downstream industries of the tourism ecosystem by leveraging the "third party generated services" such as traffic and resort ticket booking, hotel and restaurant reservations, tour guide service and location-based services that are included in the test bed of the myCourse environment.

Figure 1 illustrates the use of the tourism use case within the myCourse environment. This use case is available within the myCourse platform, as implemented by means of the corresponding tourism business scenarios, while taking advantage of the myCourse's underlying infrastructure and architecture for the deployment, use and consumption of diverse (user- and business-generated) services.

Most mainstream social networking services (SNS) around the globe are still limited in functions like friendship building, personal expression and communication, etc. In China in particular there are some SNS focusing on a professional vertical or horizontal service, though very few. Those merge businesses like B2B, B2C and C2C to fully leverage SNS' abundant user resources and unique communication opportunities. But this trend seems to be apt to start from the business circle side. For example, Tao bao, (Alibaba's consumer-focused e-commerce site), the biggest $\mathrm{C} 2 \mathrm{C}$ business in the world, first has an online community to just assist its buyers and sellers, then launches a SNS with more socialized business separately.

As one of the emerging countries, Chinese economy develops fast and contributes largely to the world's economic development. This social network framework improved by the feedback of this test case will lower barriers for service providers, in particular Small and Mediumsized Enterprises (SMEs), to develop services through the myCourse platform and interfaces.

\section{THE EMPloyment USE CASE}

This use case is based on a UK professional working at a UK Small and Medium Enterprise seeking employment in the European Union. She has many outputs relating to her professional achievements that she has collected so far during her professional life. These outputs include her qualifications, business related outputs which are mostly paper based documents but often copies in a digital format, digital artefacts like videos and photographs evidencing her achievements on Flickr, and a blog where her ideas and views could interest prospective employers. These outputs are sitting in a number of different places, and she would like to have an aggregation point to provide views of all the outputs to prospective employers.

She is looking to apply for a new job in a larger department in a different business environment. She is a

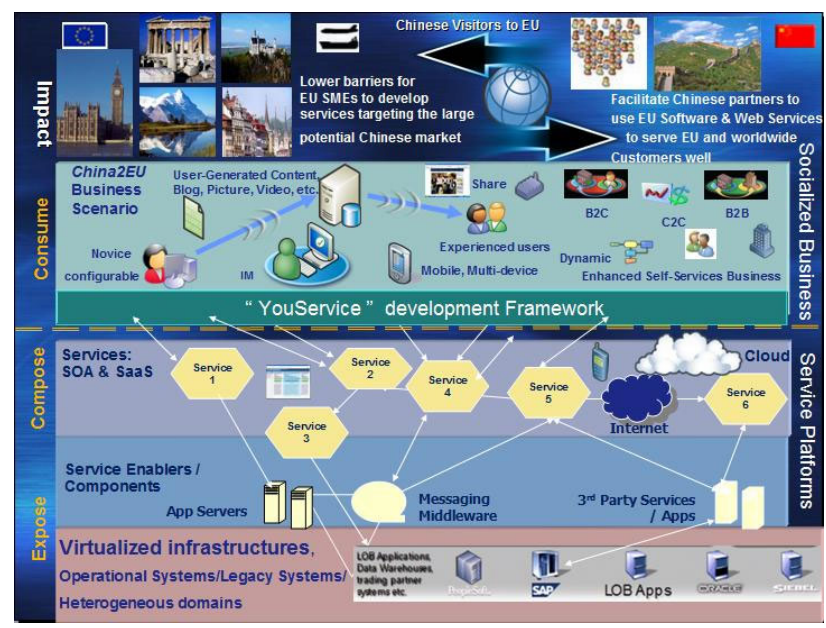

Figure 1. China 2 Europe DIY Tour Platform based on Social Network Service features of myCourse

fluent speaker of German and English and she considers career opportunities in other parts of Europe. Her only additional consideration is some element of flexibility (e.g. tele-working) that would allow her to combine childcare and achieving professional ambitions. Her steps to achieve her ambitions are as follows:

1. She registers with myCourse and she acquires an account.

2. She creates a new service of her own that aggregates all of her credentials and data related to her job seeking from different places (e.g. Flickr, YouTube, blogger.com, etc) in an e-portfolio. She searches the myCourse site to see if other people have created services to aggregate job ads that are of interest to her. If available, she looks at reviews of these services by other people who have used them in the past.

3. She contacts prospective employees and she engages in communication with them (either in the platform or externally) before being potentially invited to an interview.

4. In the end of the process she succeeds in having three offers from European employers and her needs have been addressed by the platform.

The use case has been tested having the appropriate infrastructure in place in the myCourse system by:

- Adopting an e-portfolio system to be used by candidates as an aggregation tool of all career outputs for providing views to prospective employers to showcase competences and achievements.

- Creating an aggregation tool that collects information from private employment agencies and public services on job vacancies.

Publicising these recruitment information fora to employers and job agencies to generate interest and engender communication between them and the candidates.

Each of the (business) use cases developed within myCourse serves to indicate the value of myCourse in a wide gamut of real business contexts. These use cases can be used by real users and are adaptable, configurable and mashable. The services use front ends that have been developed and which exploit myCourse's underlying platform and infrastructure. This is indicated in Figure 3. 


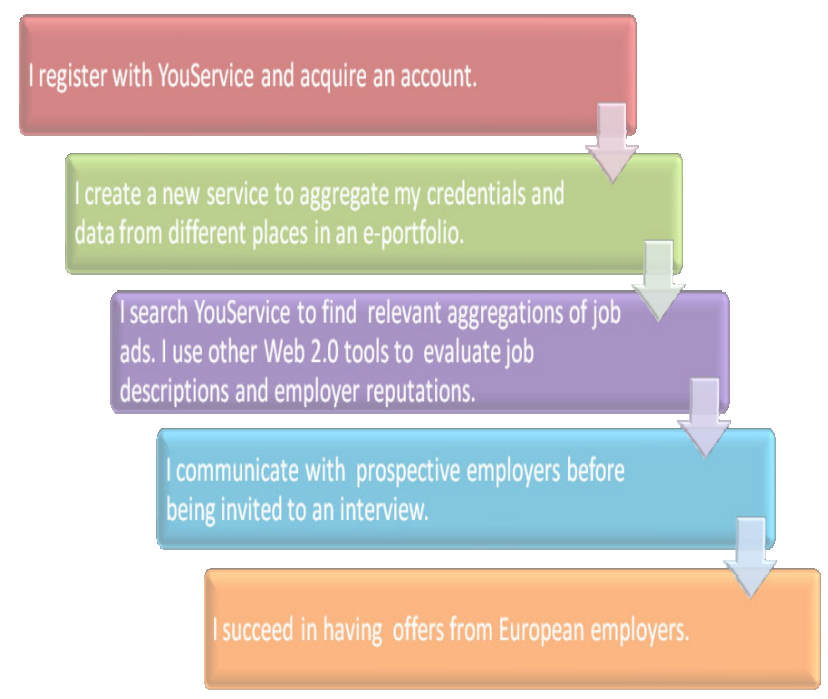

Figure 2. The employment use case within myCourse

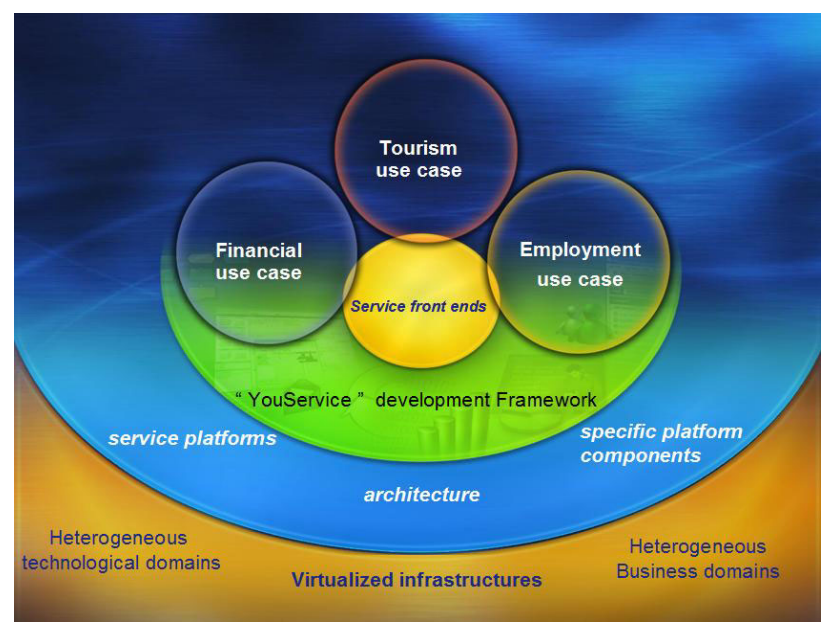

Figure 3. myCourse use cases

In the next section we elaborate on the efficiencies created by the myCourse environment and conclude with an agenda for widening the audience of uptakers and adopters.

\section{INCENTIVES FOR MYCOURSE ADOPTION: LOWERING THE BARRIERS FOR EDUCATIONAL SERVICE PROVIDERS}

myCourse is an open platform allowing the participation not only of public users, but equally of companies (and particularly SMEs) that want to create and promote their own services. For these companies, participation and active engagement in the myCourse platform (framework) allows them to:

- Explore new avenues for the marketing and promoting of their services, such as using myCourse's social network and / or nurturing virtual communities of customers and business partners.

- Tap on a wide range and base of users that can benefit from these services.

- Develop new service, chargeback and business models, while at the same time expanding activities horizontally (in Europe and further afield).

- Exploring synergies with other partners (companies) registered in the platform for the development of complimentary services and service offerings, thereby creating new business-related ecosystems.

- Gain knowledge from the "wisdom of the crowds" according to the feedback and ratings that public users leave relevant on offered services, leading to potential open innovation through "crowdsourcing". Therefore crowds (in our case the social network users and the potential complementary service providers) can play a vital role in both the creation of the service as well as in its testing / evaluation / improvement and promotion - penetration.

- Explore the design of interfaces provided by myCourse platform, as well as exploiting connectivity with external services through standardisation (such as Web Service standards) and open architectures.

SMEs that are expected to participate as business partners in the adoption process of myCourse, as well as their wide network of available synergies in the aforementioned areas will ensure that SMEs gain a competitive advantage by participating in the myCourse Framework through developed innovative service and business models.

\section{A. Strengthening the European educational service industry}

Over the past two decades, the 'service economy', which includes the service sector activities, has become a major aspect of most industrialized nations' economies according to key economic indices, such as contribution to GDP and employment. In parallel, the concept of 'service' has been developed in different disciplines, such as in computer science and software engineering, operations research, business strategy and marketing, as a key theoretical construct or a strong metaphor that affects drastically recent research initiatives.

myCourse tries to provide the conceptual and methodological foundations that reflect interdisciplinary concerns regarding research in service systems. myCourse is about cross-fertilizing disciplines to expand the common knowledge base, generate ideas, create methodologies, develop toolsets and technologies, and evaluate practices in order to investigate and invent the future of services. In this respect, myCourse aims to investigate the future of services in ICT by means of analyzing a variety of service-related concepts in a wide range of disciplines (which are represented by the business partners participating in the adoption process), including computer science, software engineering, operations research, management of information systems, economics, management theory, marketing, business strategy, cognitive sciences; transcendental elements in services, as well as novel concepts and knowledge from related areas, will also be part of the research in this environment.

myCourse ambitiously aims to shape the future internet of services (with a particularly European direction) by proposing a Framework in combination with a set of guidelines and evidence of good practice in creating a service provision platform which will enable networked users to develop their own services, add them to the network and adapt, customise and control services according to their needs. The management of services, the Service Selection protocol and the interoperability capacity (which will be an attribute of the Framework) will enable the attainment of people's needs in an environment of converged ICT, telecommunications and media platforms. 
By tapping into networked users as a means for both locating and resourcing appropriate services, instead of relying solely on automated service discovery, myCourse will increase the quality and suitability of services as well as improve the responsiveness and throughput of platforms based on the myCourse paradigm. As well as user to user (C2C) assistance within myCourse, B2C and B2B models will also be taken into account in order to provide a more competitive environment. The high user empowerment and advanced and dynamic online communities presented in the Framework will ease the creation of platforms enabling "third party generated services". Thus, the service industry would be enhanced offering greater flexibility to consumers in terms of meeting needs reliably and costeffectively.

Of course, the success of a service also depends on creativity, information sharing and collaboration among users. This will all be taken into account in the myCourse Framework which will enable future service systems to cater fully for key societal and economical needs, in particular with regards to the European area, but also considering interactions with further users abroad (e.g. China) in order to promote the needs of European (public and business) service users.

\section{B. Impact for the area of service systems}

myCourse investigates the technological background to enable the design, development and management of interoperable, reliable, resilient and secure services within the myCourse Framework.

On a deeper level however, myCourse promotes research that will provide the fundamental structures for a paradigm shift in the design, development and operation of service systems. The deep understanding of the potential of services in ICT could lead to an avalanche of innovative, constructive and exciting projects in the field. The wider impact of the work reported here is expected to affect the following:

- It will contribute in the establishment of a paradigm for the development of Service Science.

- It will boost and extend the opportunities for service innovation with ICT with respect to the development of new types of services, the application of alternative processes of service provision and the interaction with the customer at the front-end for the co-creation of value.

- It will nurture genuine innovation with services that aims at the creation of value, rather than the improvement and efficiency of business processes.

- It will foster fresh approaches on the analysis of service systems that emphasize the role of the customer, as well as culture-related aspects such as the social interaction and the co-creation of value.

In spite of the evident importance of the service economy, there is still little research in service systems and service interactions with respect to design, operation, productivity, quality and innovation. The basic reason for this is an incomplete understanding of the concept of service, in terms of the 'what tangible products are not', and a fragmented approach on the research for service systems and service interactions, with each discipline aiming at preserving its primacy on the scientific foundations of service (e.g. engineers prefer an engineering background, economists sponsor an economic base and likewise do scientists and professionals from other related fields) and restraining its perspective on specific aspects of service production and delivery. A clear manifestation of the latter is that the concept of service is found everywhere in different disciplines nowadays, such as in computer science and software engineering (e.g. SOA, web services, software-as-a-service, etc.), operations research (e.g. service operations, 'servuction', 'servitization of production', 'service factories', etc.), marketing (e.g. services marketing, service quality, relational marketing, etc.), business strategy and management (e.g. e-services, outsourcing, product packages, etc.), law (e.g. access rights, sharing right, etc.); however, there is still little connection between these concepts and limited effort to find their common roots and progression pathways. The existing confusion regarding the concept of service and the lack of affinity in research efforts reveals the absence of firm scientific foundations that will guide research in the field. However, without a shared vision and common concepts and objectives, it is doubtful that any real progress can be made that will enable significant outcomes and service innovations.

Even though the discussion about the need of a Service Science as an interdisciplinary field that will integrate existing knowledge and will develop new concepts, methodologies and tools for the improvement of service systems and the development of innovations with services originated in 2006 with the publication of a 'research manifesto for Service Science', [8], little progress has been made in this direction. Service Science remains a field that still needs to be clearly defined and almost no proof-of-concept has been produced yet, other than research agendas and some foundational work on the demarcation of the new field. Multidisciplinarity in these efforts is mere rhetoric, as inputs from other than engineering disciplines fail to be organically included in the preliminary conceptualisations of service systems. The state of the art reveals, in general, that, even though the need for interdisciplinary effort is recognized by everyone, each discipline tries to make progress independently, with the hope to meet the others en route. In a similar way, previous research at European level hasn't contributed largely in this direction, as most efforts were focused on developing technical and technological solutions, setting aside both the epistemic aspects of services and their use by people, communities and organisations in the context of real life situations. As a result, we may have produced engineering methodologies, software architectures, powerful languages, smart techniques and state-of-the-art toolsets, but we haven't understood how we can use them to produce innovations that reflect on real life situations.

The claim for the development of a Service Science is a thunderous acknowledgement that the existing theories, models, methods and toolsets are not able to produce innovations in a service-based world. If the future is in services or with services, then a new paradigm is necessary that will put the logic in every aspect of technological research and development.

myCourse will challenge recent research in services and will tackle the present shortcomings in the development of a paradigm for a Service Science by broadening the scientific scope, applying a truly multidisciplinary and transdisciplinary approach in the study of service systems and assimilating this broad range of aspects to the field of ICT. The research work presented here provides a stage for the 
fusion of new ideas from a variety of disciplines that expands the mental boundaries of service systems and moulds an integrative framework for understanding service interactions and service provision.

\section{CONCLUSIONS}

We conclude the presentation of the three application scenarios realised by means of myCourse by describing what we consider as breakthroughs of myCourse in the addressed domain:

- It provides a stage for the cross-fertilization of new ideas in service research to expand the intellectual boundaries in service interactions and search for alternative paradigms, by blending scientific knowledge and business requirements with service consumer user requirements related to service provision and by considering transcendental elements of people's personal and working lives and organisational practices.

- It provides a conceptualisation for a 'world of services' and for the future of the Web. It is not difficult to predict a future with global service infrastructures (some of which already exist), multilingual services that understand natural language or services which can supply customised service delivery and make any of their customers or consumers happy. On the other hand, potential exploitation of such services demands caution: a 'world of services' is open to collapses of 'service economies', due to potential 'service terrorism' (e.g. provision of bogus services to damage the reputation of service providers or service systems) or 'service anarchy' (e.g. jamming the e-commerce sites with huge number of simultaneous connections); also, it leaves room for the emergence of multifarious novel socio-technical phenomena, such as 'service activism' (e.g. for the co-creation of value in virtual communities), 'service democracies' (e.g. which, when unorganised, cause ineffectiveness and discouragement for providers, perhaps by ignoring all past performance and giving all service providers the same exposure to customers) or, at the other extreme, 'service tyrannies', (e.g. causing without ration the total hierarchic control of the exposure of service providers by a few nodes).

- It provides a universal framework for the study of service systems as collaborative knowledge creation and advancement systems. Service is considered a knowledge-based process for the co-creation of value through the interaction of various / multiple service (sub-) systems. Service systems are normative structures that facilitate the collaborative knowledge creation and advancement (i.e. improvement of existing knowledge) between the provider and the customer. Hence, the value of a service interaction can be considered as equal to the knowledge it creates collaboratively, regardless whether this knowledge remains with the customer or with the provider (or it is shared with another entity or the society).

- It drives service research from the consumer's point of view. Up to date research is dominated by provider-oriented approaches that focus on production and delivery issues, such as productivity, efficiency and competitive advantage, but overlook the customer's perspective (especially when the customer is an individual or consumer). Such approaches lead inevitably to gaps in the perception of service from providers and customers. myCourse moves one step forward and tries to close these gaps, by providing a universal framework for understanding service interactions and service value.

- It provides an ecosystem approach on service interactions. Customers and providers interchange roles constantly, being one time producers and some other time receivers of services. Since service interactions mean to provide some benefit to the customer in order to resolve problems or meet particular needs, the complexity of customer problems or everyday practices should determine the complexity of service interactions.

\section{REFERENCES}

[1] T. Giouvanakis, G. Fragidis, I. Ignatiadis, and A. Koumpis. myCourse: an educational content management platform with social networking characteristics, International Journal on Emerging Technologies in Learning (iJET) Vol. 5, No. 4, 2010. doi:10.3991/ijet.v5i4.1450

[2] S. Lamparter, D. Oberle, and C. Weinhardt. A policy framework for trading configurable goods and services in open electronic markets. ACM International Conference Proceeding Series Vol. 156: Semantic web ontologies, rules, and services track, 2006, pp. 162-173.

[3] T. Giouvanakis, G. Fragidis, D. Paschaloudis, and K. Tarabanis. "Embedding a vocabulary-based application for concept mapping into a learning management system", Open Education Research, ISSN: 1007-2179, Vol. 11, No 5, Oct. 2005, pp. 38-43, 2005.

[4] T. Giouvanakis, H. Samaras, D. Bousiou, and K. Tarabanis. Multiple Ways of Enriching a Web-based Learning Environment through Concept Maps. In P. Kommers \& G. Richards (Eds.), Proceedings of the ED-MEDIA 2005, Association for the advancement of Computing in Education (AACE), 2005, pp. 4212-4220. Chesapeake, VA: AACE.

[5] Keil, M. Pulling the Plug: Software Project Management and the Problem of Project Escalation, MIS Quarterly, Vol. 19, nr. 4, 1995

[6] The Markets in Financial Services Directive, Directive 2004/39/EC, Official Journal of the European Union. 2004.

[7] P. Gomber, and M. Chlistalla. Implementing MiFID by European execution venues - Between threat and opportunity, Journal of Trading, Spring 2008, Volume 3, Number 2, pp. 18-28, 2008.

[8] H. Chesbrough and J. Spohrer, (2006). "A Research Manifesto for Services Science" Paper presented at the Communications of the ACM, July 2006.

\section{AUTHORS}

Dr Thanasis Giouvanakis holds a $\mathrm{PhD}$ from the University of Macedonia, Thessaloniki, Greece on "Designing and developing adaptive e-learning systems in a semantic web environment". He also holds a Masters in Information Systems from the same university and a Diploma in Physics from the Aristotelian University, Thessaloniki, Greece.

His research interests are in the areas of e-learning, Semantic web, Software design and development and multimedia systems. He is a researcher in the Information Systems Laboratory at the University of Macedonia (team of Professor Konstantinos A. Tarabanis).

Currently he works with ALTEC on an internal project for Business Games in Immersive Environments. (email: thgiouv@uom.gr)

Adamantios Koumpis heads the Research Programmes Division of ALTEC S.A., which he founded at 1996 (then as independent division of Unisoft S.A.). Adamantios holds a $\mathrm{PhD}$ degree from the University of 
Kingston, UK and a Bachelor degree from the University of Crete, Greece. (email: akou@altec.gr).

Garyfallos Fragidis is Lecturer of Business Information Systems at the Department of Business Administration. He currently teaches E-commerce, Management Information Systems and Database Analysis and Design. He is the head of the Entrepreneurship Centre of the Technological Education Institute of Serres. His research is mostly related to the strategic and organizational aspects of electronic business. His current research focuses on service models for value co-creation and customer-centric aspects of electronic business. In the past he was engaged in research related to e-business models, e-services, business ecosystems, e-government and knowledge management. (email: garyf@teiser.gr).

Submitted November $29^{\text {th }}, 2010$. Published as resubmitted by the authors March $1^{\text {st }}, 2011$. 